\title{
Digital holography in optics labworks
}

Lionel Jacubowiez, Thierry Avignon, Xavier Mininger, Fabienne Bernard

Lionel Jacubowiez, Thierry Avignon, Xavier Mininger, Fabienne Bernard, "Digital holography in optics labworks," Proc. SPIE 9664, Ninth International Topical Meeting on Education and Training in Optics and Photonics, 96642J (24 October 2005); doi: 10.1117/12.2207682

SDE Event: Ninth International Topical Meeting on Education and Training in Optics and Photonics, 2005, Marseille, France 
Ref ETOP026

\section{Digital holography in optics labworks}

Lionel Jacubowiez, Thierry Avignon,, Xavier Mininger, Fabienne Bernard

Ecole Supérieure d'Optique, Bâtiment 503 - Centre Universitaire, 91403 Orsay cedex Fabienne.Bernard@iota.u-psud.fr

\section{Abstract}

The paper describes the digital holography experimental bench we used in our engineering school and the results we can acheived for two kind of measures :

1. displacements on the surface of a little plate which can be deformed by a PZT actuator, 2. amplitude of the vibrations when the PZT is excited by a sinusoidal signal.

This experiment bench have also been used for vibration mode analysis of an electrical motor in collaboration with a research laboratory.

It is a very useful experiment to teach techniques using coherent light, and also features of numerical acquisition of images.

\section{Keywords}

Computer holography, speckle interferometry, vibration analysis.

\section{Introduction}

\section{Summary}

Digital holography provide images of submicrometer displacements on an object surface. These techniques allows to analyse vibrating structures.

Classical holography can now be advantageously replaced by these computeb ased techniques for industrial measures.

Our experimental bench allows the students to discover several measurement techniques based upon such digital holography devices. 


\section{Experimental bench}

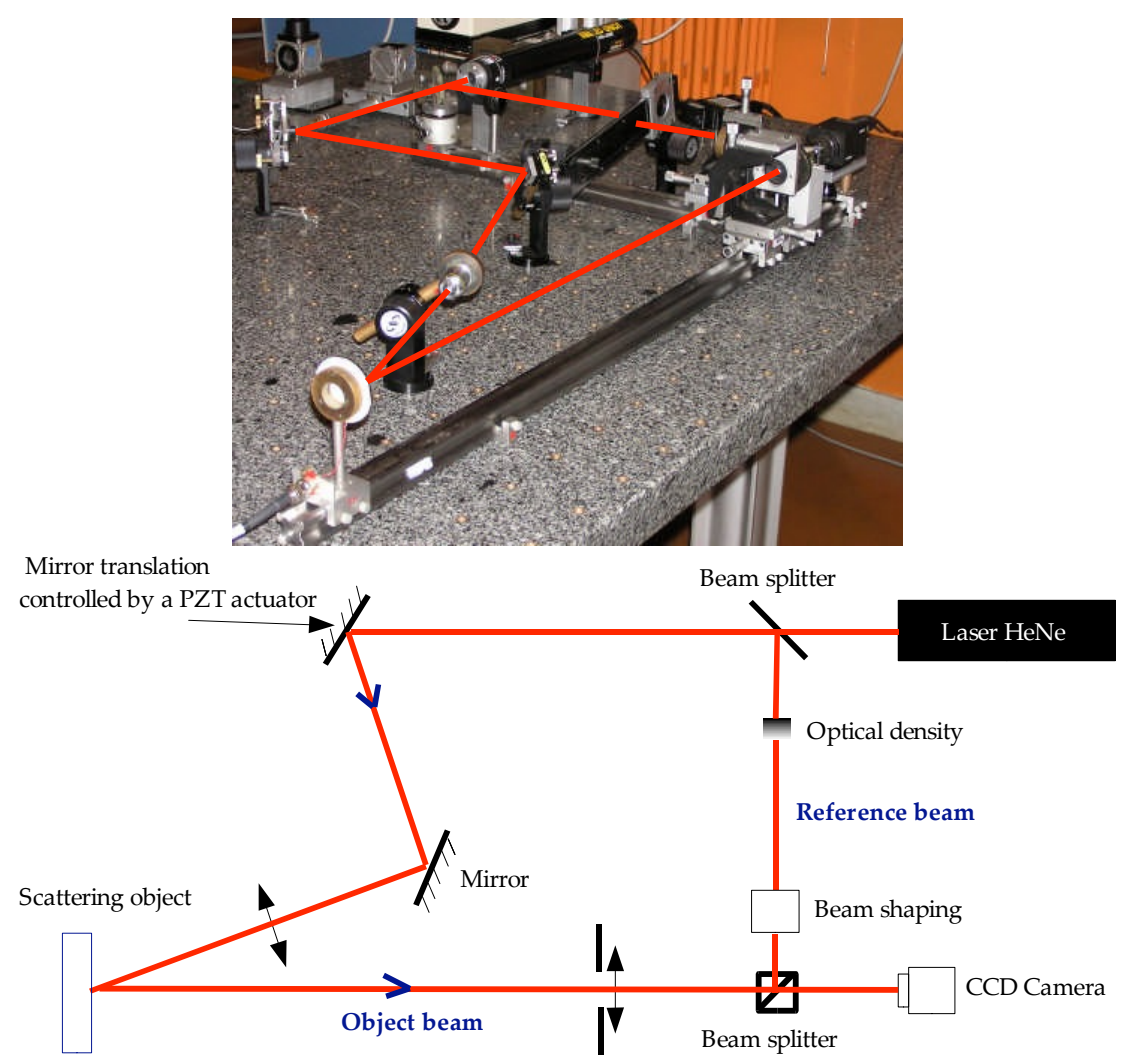

Figure 2. Experimental bench description

We observe with a CCD camera the interference pattern between a laser beam reflected by the object to be analysed, and a reference channel.

The object is a little plate, a PZT actuator can apply a static deformation of its surface or excite vibration modes according to a DC ou sinus excitation. 


\section{Brief labworks description}

\subsection{Speckle analysis}

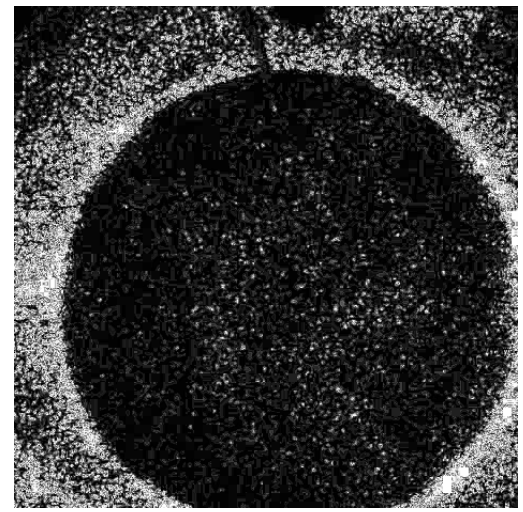

Figure 3 Exemple of a speckle pattern

As the object scatters light, we observe speckle patterns on interference images (Figure 2). Then the first object of study in this experiment is speckle.

The CCD camera is linked to a computer, some numerical processing allows the students to adjust the experimental parameters to optimize the visualization of interference patterns.

\subsection{Displacements measurement}

To measure displacements on the plate surface, two methods can be performed. The principle is always to compute the numerical difference between two images, pixel by pixel:

1. direct interference patterns, before and after deformation of the plate.

2. or both obtained by phase-shift method using 4 ou 5 different images, stored after little shift ofthe light phase. This phase shift is performed by a second PZT which move a mirror for a chosen distance less than the wavelength.

In this two cases, the result is an image which measure the variations of phase, on the laser beam reflected by the object, due to the deformation.

\subsection{Vibration analysis}

The refresh frequency of the camera is $50 \mathrm{~Hz}$, therefore, when the plate vibrates at frequency near $10 \mathrm{kHz}$, our device integrate vibration signal. However, numerical processing allows to have a measure of amplitude of vibration along the surface of the object. Indeed, it can be shown that two methods derived from the previous ones can give a map of the vibration mode as schown in figure 3. 


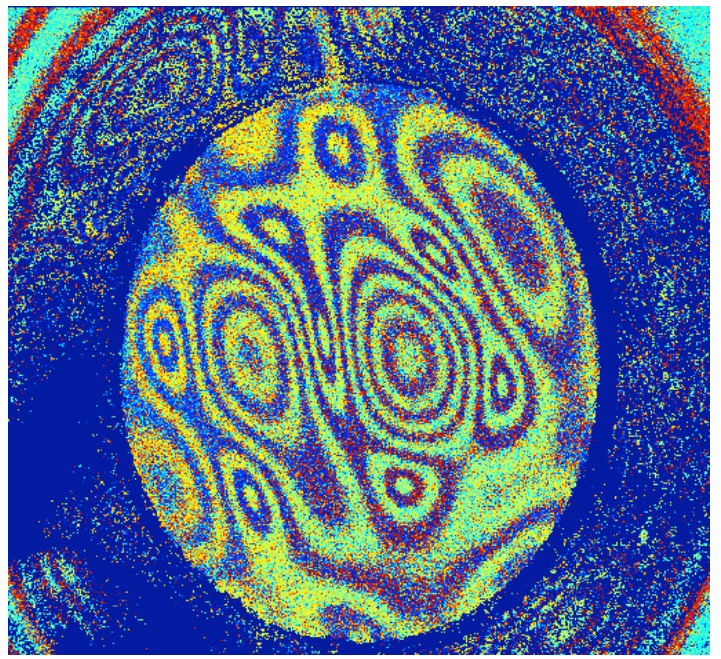

Figure 4 Vibration analysis of the PZT plate

\subsection{Application}

The vibration of the structure of an electrical motor causes accoustic noise. This experimental bench has been used to analyse the vibration modes of an electrical motor. Some students have performed theses measures in an experimental project.

All theses experiments give spectacular images and provide valuable teaching support. 